\title{
Interaction between habitat limitation and dispersal limitation is modulated by species life history and external conditions: a stochastic matrix model approach
}

\author{
P. Fibich ${ }^{1,3}$, A. Vítová1 and J. Lepš ${ }^{1,2}$ \\ IDepartment of Botany, Faculty of Science, University of South Bohemia, Branišovská 1760, České Budějovice, \\ Czech Republic \\ 2Institute of Entomology, Biology Centre CAS, Branišovská 31, České Budějovice, Czech Republic \\ ${ }^{3}$ Corresponding author.Email: pavel.fibich@prf.jcu.cz
}

Keywords: Annuals, Carrying capacity, Dispersal limitation, Habitat limitation, Perennials, Seed bank.

\begin{abstract}
Traditionally, species absence in a community is ascribed either to dispersal limitation (i.e., the inability of propagules of a species to reach a site) or to habitat limitation (abiotic or biotic conditions of a site prevent species from forming a viable population); sowing experiments can then distinguish between these two mechanisms. In our view, the situation is even more complicated. To demonstrate the complexity of the problem, we designed and applied simulations based on an extension of matrix models covering effects of propagule pressure and habitat limitation, and reflecting various characteristics of a species and of a habitat. These included life history, fecundity, seed bank viability of a species, habitat carrying capacity and disturbances. All the investigated factors affected proportion of occupied habitats. Whereas they can, to a large extent, compensate for each other, simultaneous decrease of habitat suitability and propagule input can be detrimental to the survival of a population. Our model demonstrated that in many cases, the absence of a species in a community is of stochastic nature, and result of interaction of species life history and various external conditions, and thus cannot be simply attributed to a single cause. The model results are supported with examples of case studies. The results also explain some well-known ecological phenomena, as decrease of niche breadth from the center to the margins of area of distribution. Finally, the model also suggests some caveats in interpretation of the results of sowing experiments.
\end{abstract}

\section{Introduction}

The search for determinants of species composition of ecological communities is one of the basic tasks of community ecology (Silvertown and Charlesworth 2001, Vellend 2016). Any species found in the community must have been able to arrive to the site, to establish a population there, and that population must survive there until we have sampled the community. Failure in any of these three processes (arrival, establishment, survival) results in the absence of a species. Understanding why species are missing from the communities is necessary for understanding the diversity decline, and also for designing effective management measures.

Traditionally, species absence in a community is considered to be a result of two possible constraints, i.e., dispersal and habitat limitation. If species are not able to reach the site, we talk about dispersal limitation (Ehrlén et al. 2006, Foster 2001, Primack and Miao 1992, Zobel et al. 2000). Species that are not able to establish and survive in the community, even if its propagules are present, are considered to be habitat limited (Dupré and Ehrlén 2002, Moore and Elmendorf 2006, Turnbull et al. 2000). Habitat limitation encompasses here both the biotic and abiotic enviromental filters, i.e., the biotic interactions of other species, in the case of limitation, this is mainly competition (Jakobsson and Eriksson 2000,
Fibich et al. 2013, Wellstein et al. 2014, Švamberková et al. 2017), but also possible effects of pathogens, herbivores etc. (Orrock et al. 2006, Moles and Westoby 2004). Vellend (2016) involves these processes under the "high-level process" called selection. Dispersal and habitat limitation are thus two factors affecting species composition of communities, usually considered as independent of each other, even though they operate jointly and can compensate each other (Clark et al. 2001, 2007), and their interactions can be quite complicated (Pásztor et al. 2016). Their effect is often demonstrated through seed addition experiments - successful establishment of originally missing species after seed addition is often considered as a demonstration of dispersal limitation, whereas species unable to establish at a site are considered to be habitat limited (Turnbull et al. 2000).

This strict separation is (tacitly) based on the idea that there are habitats suitable for a species and habitats that are not suitable. In suitable habitats, once a species arrives, it establishes a viable perpetuating population. Its absence on other similar habitats is thus caused by dispersal limitation. On the contrary, in unsuitable habitats, the species is not able to form a population, or if the population is established, it (sooner or later) dies out (Foster and Tilman 2003, Klimeš 2005, Moles and Westoby 2002, Primack and Miao 1992). Nevertheless, in seed sowing experiments, introduced species 
are sometimes able to overcome negative community filters and establish there through high seed input solely (Mudrák et al. 2014, Vítová and Lepš 2011), and in this case it is important to follow the population to be sure that it was able to form a viable population. On the other hand, for many clonal plants, the establishment from seeds is a rare event, and even resident species are not able to establish from seeds (Vítová and Lepš 2011). Colonization of new, not yet occupied sites is a bottleneck process where seed input must be sufficient to provide enough individuals to be able to establish and overcome habitat filters. Environmental constraints on life stages after germination are species specific (Baeten et al. 2009). In many studies, we can find a general trend of high densities of seedlings but low densities of adults during establishment phase (Turnbull et al. 2000).

The importance of dispersal limitation is still under debate (Baeten et al. 2009) and apparently differs among community types. For example, its role in extreme Mediterranean conditions was small in comparison with habitat filters (Goméz-Aparicio 2008). On the contrary, Baeten et al. (2009) argue that environmental limitation cannot be a crucial factor for species absence in a forest and that dispersal and habitat limitation are non-exclusive mechanisms that shape the composition of a plant community. Gustafsson and Ehrlén (2002) reached a similar conclusion in their study of forest species. Our experience shows that the situation is even more complicated. In particular, the chance that a seed will establish an individual is very small, even for species that are resident in the community. Often, the community filter affects mainly species regeneration from seeds. In our sowing experiment (Vítová and Lepš 2011), only 7 adult individuals had established from 2000 sown seeds of Plantago lanceolata, a resident species common in the community. For all other tested species, both resident and newly introduced, the establishment success was even lower. Consequently, even for species well adapted to a habitat, many seeds must reach the site for the species to have a chance to establish there, the higher the amount of seeds arriving, the higher the chance will be that at least some of them will ,sneak" through the community filter and will give rise to an established individual (which will produce seeds, ideally for many years, and eventually enables establishment of viable population). Apparently, the stricter the habitat filter is for species establishment, the more seeds are needed to overcome it (Clark et al. 2007).

Further, there is a chance that each population may become locally extinct (for various reasons, including demographic stochasticity or environmental fluctuations), and the probability of this depends also on the species life history. A species can be missing in a site, despite the fact that it arrived and established a population there, but subsequently, the population became locally extinct. Species dependent on continuous influx of diaspores are called transitional according to Grime (1998), or their populations are considered sink populations in the metapopulation theory (Hanski 1997, 2004). However, the classification of population types is definitely not a sharp one, and even seemingly well-established populations can die out (e.g., due to extreme weather conditions, local disturbance or due to a "pest"). Nevertheless, large local populations (populations with large carrying capacities in the metapopulation theory terminology) are less affected by demographic stochasticity, and also less likely to become extinct.

All the above mentioned mechanisms are stochastic in their nature - each seed has some (usually very small) probability to develop into an established individual, each individual has some probability to die, adverse events (like major disturbances) appear also with some probability. The presence/absence of a species in a site is then a consequence of many stochastic events. Naturally, for many species and habitat combinations, probabilities are close to zero, for some they can be close to one, but in many cases, they are somewhere in between. Pärtel et al. (2011) use the term dark diversity for set of species with high probabilities of occurrence, but still absent from the community. Whereas these probabilities are obviously specific for each species - habitat combination, there are also some general patterns determined by traits and life histories of the species considered. For example, increasing seed size will mostly increase the species chance to establish from seed, but will increase its dispersal limitation (Jakobsson and Eriksson 2000).

To demonstrate how the processes of new colonization, population establishment, population survival and stochastic event frequency are interconnected, we have built a stochastic population based model, including the above mentioned processes. Our aim is to demonstrate the effect of habitat favorableness (for various population processes), population life history and propagule pressure on the probability that a habitat patch will be occupied by a species. In this way we want to demonstrate how the processes are interconnected and test to what extent they can compensate each other.

\section{Model}

\section{Concepts}

We constructed a simulation model, which reflects the three components that determine the presence of a species in a site, i.e., the propagule pressure, the properties of a habitat, and the life history of a species. In our model, we adopted some concepts of the metapopulation theory (Hanski 1997) and characterized each local population by a transition matrix model (Caswell 2001), amended with effects characterizing the propagule pressure and carrying capacity of the habitat island. The classical matrix model mostly does not take into account the negative density dependence (and hence the population can grow indefinitely, but see chapter 16 in Caswell 2001). On the contrary, the carrying capacity (in fact the equilibrial population size, determined by both habitat favorableness and habitat patch size) is one of the crucial determinants of local population survival (Hanski 1997, 2004). Matrix models for each species are characterized by its "optimal parameters", i.e., generally by transition probabilities between life stages (Foster and Tilman 2003) under optimal conditions, and these might be reduced by "habitat limitation", which can reduce both the seedling establishment 
Table 1. Values and meaning of parameters and constants for each time step. $\mathrm{P}[\mathrm{x}]$ denotes probability of $\mathrm{x}$.

\begin{tabular}{lll}
\hline Parameter & Default value, range & Meaning \\
\hline$E$ & $0.03,0.03$ (low) to 0.28 (high) & (Disturbance probability), how often disturbances happen \\
$b$ & $0.2,0.02$ (low) to 0.6 (high) & (Seed bank viability) P[seeds survive to next year] \\
$s 0,5$ (low) to 500 (high) & $\begin{array}{l}\text { Number of seeds produced by one adult plant } \\
\text { (Propagule pressure) Number of incoming seeds from } \\
\text { outside } \\
\text { (Carrying capacity) Maximal allowed number of adults }\end{array}$ \\
$i$ & 20,20 (low) to 420 (high) & (Habitat suitability/limitation) Factor for habitat suitability \\
$c$ & 100,2 (low) to 200 (high) & \\
$h$ & $1,0.1$ (low) to 1 (high) & $\begin{array}{l}\text { Factor for reducing population size during disturbance } \\
\text { (Germination) P[from seed that will become a plant] }\end{array}$ \\
\hline$R$
\end{tabular}

* It depends on the chosen type of plants, for perennials small plant and for annuals adult plant.

probability, and transition probabilities in the transition matrix model. Disturbance events decrease survival. They are characterized by frequency (how often they appear) and intensity (the extent to which they decrease survival). The propagule pressure can lead to establishment of new individuals, regardless of whether there is a seed input from local plant individuals (the phenomenon called the rescue effect).

\section{Model realization}

In our model, we focus on the explanation why a species is missing from a site. The individual sites are in fact replications of a simulation and used to estimate the probability that a site (habitat island) will be occupied under given conditions. We varied parameters characterizing the favorableness of habitat conditions, life history traits of a species, and

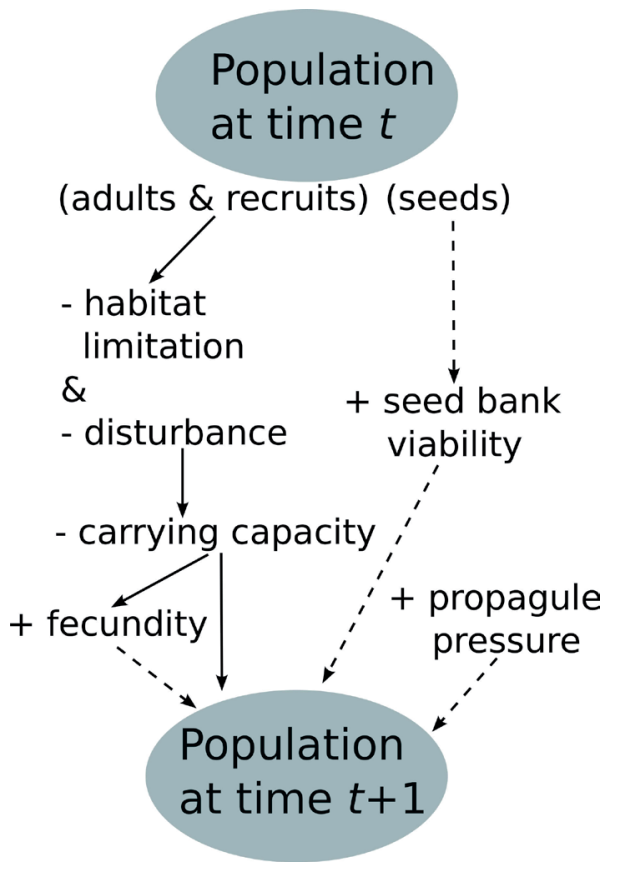

Figure 1. Conceptual diagram of matrix population model describing positive $(+)$ and negative $(-)$ effects on the population (all life stages including seeds) between time steps. Solid lines correspond to adult plant and recruits pathways and dashed lines describe seeds dynamics describing dispersal limitation. propagule pressure, that contrary to metapopulation models is taken as an external variable, which is not affected by the percentage of occupied habitat islands (Table 1). Survival of a local population is negatively affected by random events (called disturbances here).

The basic idea of our approach is simple - for each combination of parameters (Table 1), we run the population matrix model simulation for 1000 steps (years; see Fig. 1 for processes operating in transitions of the plant population between years) and check whether the population is present at the end of simulation (presence is defined here as presence of at least one adult individual). Combination of parameters remains constant during the entire simulation. We consider the 1000 year period to be roughly corresponding or longer than is the time scale at which these processes operate in contemporary landscape (we also checked that the results do not change further in time; see Fig. S1). By running the simulation 1000 times, the proportion of occupied sites is the estimate of the probability that a site will be occupied. For simplicity, we have "designed" just two life histories - annual and perennial plants, as the most common species types in the majority of seed addition experiments. Moreover, we expect different effects of the modeled parameters for these two life histories (both use the same values of parameters).

\section{Matrix model}

We designed a matrix population model for plant populations assuming two life histories (annual and perennial) and different life stages (Caswell 2001; Fig. 1). Two life stages were considered for annuals (seeds and adult plants) and three stages for perennials (seeds, small plants and adult plants, with only adult plants producing seeds). Transition formula between year $t$ and year $t+1$ has common form (for the parameter values see Table 1)

$$
\boldsymbol{n}(t+1)=f(\boldsymbol{A} \boldsymbol{n}(t)+\boldsymbol{r})
$$

where $\boldsymbol{n}(t), \boldsymbol{n}(t+1)$ are state vectors with numbers of seeds and plants at time $t$ and $t+1, \boldsymbol{A}$ is the transitional matrix, $\boldsymbol{r}$ is vector for a propagule pressure effect (with the same dimension as vector $\boldsymbol{n})$. The propagule pressure effect is a vector, for annuals $\boldsymbol{r}=(i, 0)$ and for perennials $\boldsymbol{r}=(i, 0,0)$, where $i$ 
denotes the number of seeds that are arriving to the site from outside each time step (e.g., year). The function $f$ is the probabilistic rounding function used for returning integer number of units (seeds and individuals) with a given probability. It rounds up arguments (one number or several members in a vector) with probability given by non-integer part of arguments, and it rounds down with complementary probability. For example, $f(3.4)$ returns 4 with probability $(\mathrm{P})=0.4$ and it returns 3 with $\mathrm{P}=0.6$. (In this way we avoid the non-integer numbers of individuals, and in fact enable extinction of a population - otherwise in the matrix model, a fraction of a single individual would be always present.) To constrain growth of the populations, the model applies a carrying capacity with a maximum of adult individuals set to $c$ parameter. After applying transitional formula (Eq. 1), if there are more adult individuals than $c$, number of adults is set to $c$ and other adults are considered as dead due to negative densitydependence (i.e., competition).

\section{Transitional matrix for annuals}

For annuals, $\boldsymbol{n}=\left(n_{1}, n_{2}\right)$ is a transposed state vector, where $n_{1}$ is number of seeds and $n_{2}$ is number of adults. The transition matrix is

\section{$A=\left(\begin{array}{cc}b & s e \\ G h e & 0\end{array}\right)$}

where $b$ (seed bank viability) is the probability that a seed survives ungerminated in the soil to the next year (so, seeds in the soil are expected to be depleted exponentially, so values close to one mean long lasting - "persistent" seed bank), $s$ (fecundity) is the number of seeds produced by one adult plant, $G$ (germination) is the probability that a seed will germinate and establish into an adult plant under ideal conditions, $h$ (habitat) is a factor expressing habitat limitation of seed recruitment ( 0 would mean that no seed is able to establish, 1 would correspond to ideal conditions). Value 0 denotes that all adult plants die after a year. Factor $e$ represents a disturbance event (i.e., event that kills part of population, for example, a winter too long and/or cold, fire or pest outbreak). It is determined by two parameters, the frequency of disturbances $E$ and the strength of disturbances $R$ (higher value denotes lower reduction). The parameter $e$ then refers to

$$
\mathrm{e}=\begin{aligned}
& \mathrm{R} \text { with probability } \mathrm{E} \\
& 1 \text { with probability } 1-\mathrm{E} \text {. }
\end{aligned}
$$

Monte Carlo simulation decides in each time step (i.e., year), whether the disturbance event happens or not.

\section{Transitional matrix for perennials}

The transposed state vector for perennials is $\boldsymbol{n}=\left(n_{1}, n_{2}, n_{3}\right)$, where $n_{1}$ is number of seeds, $n_{2}$ is number of small, i.e., nonreproductive plants and $n_{3}$ is number of reproductive adults. The transitional matrix is

$$
\boldsymbol{A}=\left(\begin{array}{ccc}
b & 0 & s e \\
G h e & 0 & 0 \\
0 & h e & h e
\end{array}\right)
$$

where $b, s$ and $e$ have the same meaning as for annuals. The parameter $G$ is the probability that a seed will establish as a small individual and $h$ is a parameter describing overall habitat suitability (low values mean strong limitation) operating on all stages of plants (for simplicity, we expect the same effect on all life stages). Zeros mean impossible transitions (so we do not expect that an adult plant could become a small plant in the following year, which is a simplifying assumption, just to avoid an increase in the number of varying parameters).

\section{Parameters, setting and simplifications}

Each simulation started with an empty population state vector $n$. We used values for parameters (if they are not varied) the same as those in Table 1. Our model does not consider any spatial arrangement and does not implement density dependent mortality or growth. The model is mostly deterministic except disturbance events that dramatically influence the population dynamics. The simulation code was implemented in language $\mathrm{C}$ and is available from the authors upon request.

\section{Results}

Our results show that only the most favorable combinations of all the factors studied lead to habitat occupancy probability being close to one. All the factors investigated are able to affect this probability, and their effects can be mutually compensated (but can also reinforce each other). Factors important for dispersal (e.g., propagule pressure) and fecundity became more crucial as habitat limitation gets stronger (e.g., under low habitat suitability, or high disturbance probability; Fig. 2). Both the propagule pressure and habitat limitation could change the proportion of occupied patches. Generally, at a site which is suitable for species recruitment, relatively low seed input from outside is sufficient to successfully establish a population. By contrast, species may overcome unfavorable site conditions by higher continuous propagule pressure, or species may be compensated by high viability of the seed bank and so substitute high habitat limitation or low carrying capacity (Fig. 3, 4). Besides that, low plant fecundity or low seed bank viability could be balanced by higher propagule pressure (Fig. 2, 4, S5, S7). In general, the high occupancy of patches can be achieved either by their high environmental favourability (i.e., easy establishment and low probability of local extinction once established) or by high constant propagule pressure from the surrounding area. High frequency and intensity of disturbance (leading to frequent local extinctions) increases the importance of continuous propagule influx (Fig. 2, S5).

For perennials, the proportion of occupied patches tends to be more dependent on habitat limitation than for annuals, as was also the case for propagule pressure (Fig. 2, S5 vs. S2, S8). Annuals were more dependent on the combination 
of habitat suitability and propagule pressure, and under high disturbance frequency, the trend of annuals is even followed by perennials. Also, annuals were more directly dependent on seed input (whatever source it was, i.e., propagule pressure, fecundity or seed bank), contrary to perennials, which reacted more strongly to habitat limitation (i.e., habitat suitability and carrying capacity). In particular, (1) there were stronger dependences of annuals than perennials on the fecundity (Fig. 2, S5 vs. S2, S8) and on the seed bank viability (Fig. 4, S7 vs. S4, S10) and (2) the opposite was observed for the carrying capacity, which was more strongly linked with perennials than with annuals; effect of carrying capacity was mostly negligible for annuals (Fig. 3, S6 vs. S3, S9). Here, for the proportion of occupied patches, capacity/number of adults was more crucial for perennials than for annuals. High seed bank viability substituted propagule pressure more for annuals than for perennials (Fig. 4, S7 vs. S4, S10).

\section{Discussion}

Our model demonstrated effects of multiple determinants of species presence in a habitat, which can partially com-
Habitat suitability 0.3
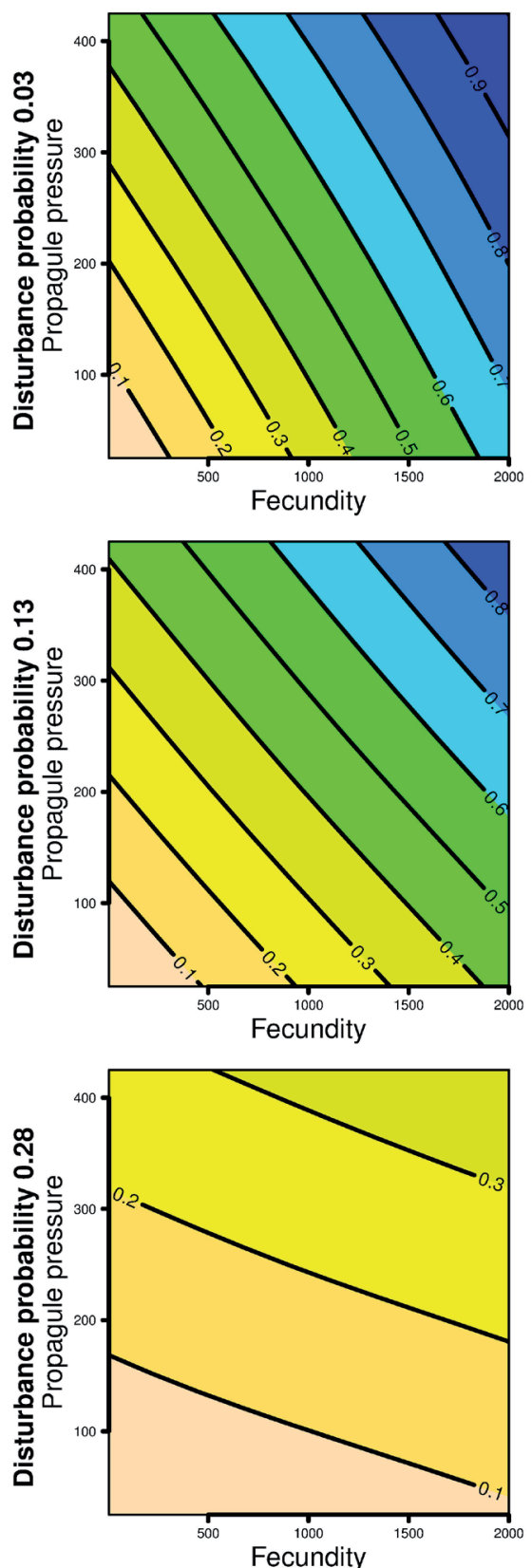

Habitat suitability 0.5
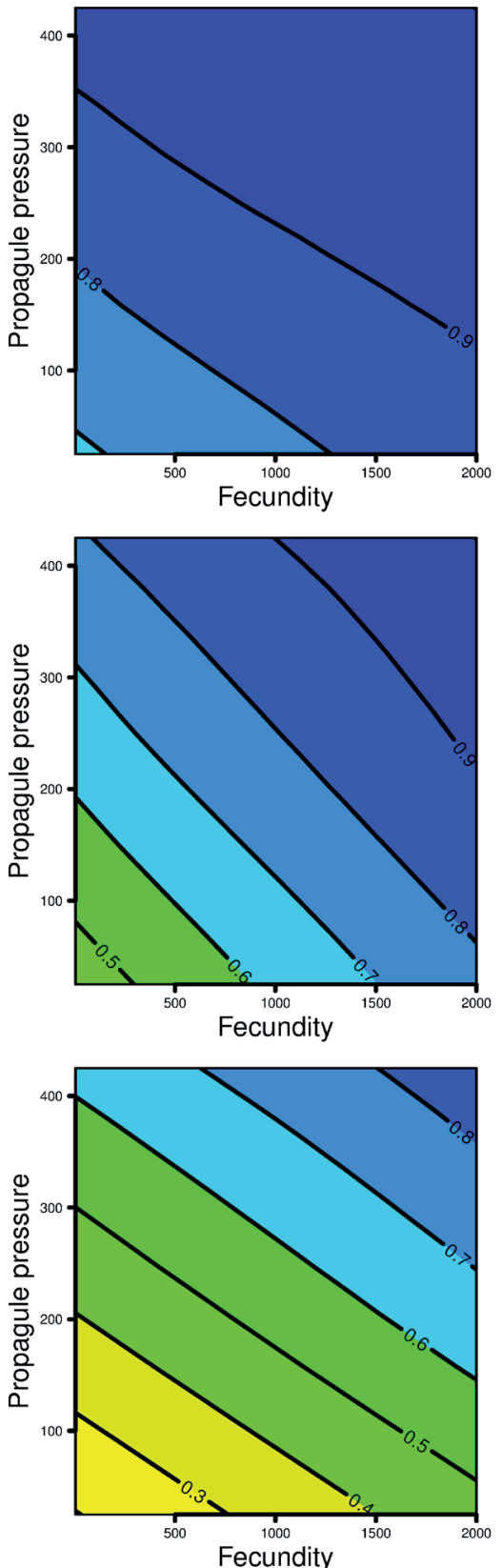

Habitat suitability 0.8
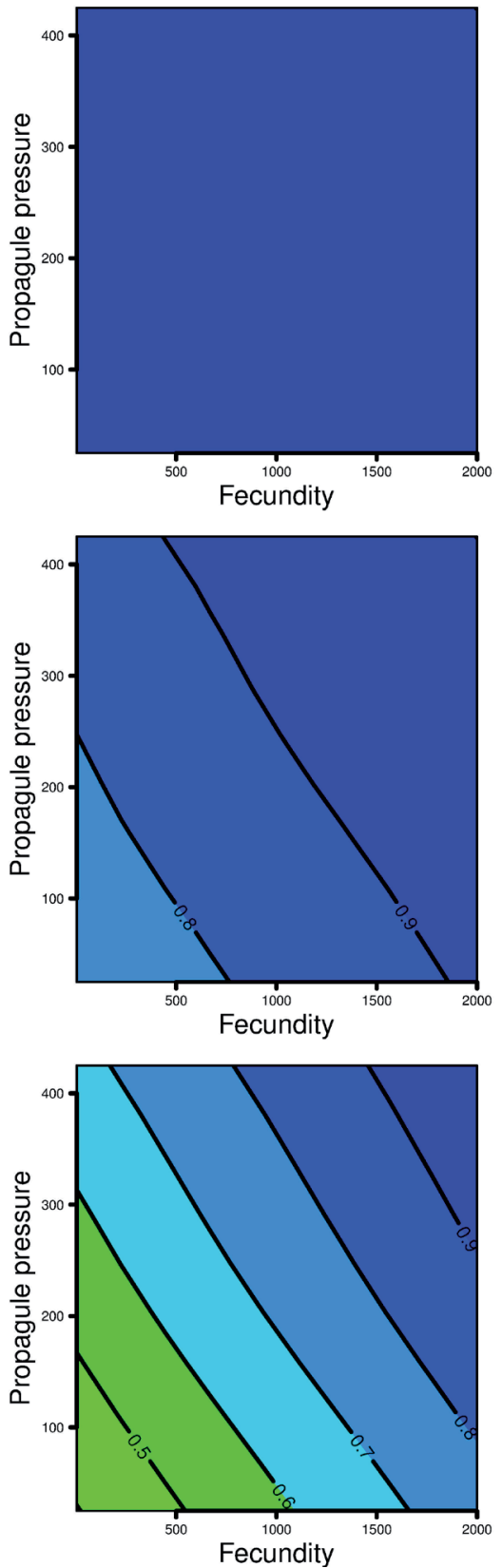

Figure 2. Proportion of sites occupied by at least one adult perennial plant from 1000 repetitions after 1000 time steps for gradients of fecundity, propagule pressure, disturbance probability and habitat suitability. Dark color (high proportion) describes parameter's space where mostly all simulations finished with at least one adult individual at the end, whereas light color (low proportions) corresponds to low number of simulations with adult individuals. For the definitions of parameters, see Table 1. 
pensate for each other. The presence/absence of a species is an outcome of various interacting stochastic processes, and thus, it might be impossible to unequivocally determine the cause of possible species absence. There are always species, for which the probability of occurrence at the site is high, but are still absent and the term dark diversity is coined for them (Pärtel et al. 2011, Pärtel 2014). The first constraint, and probably the most obvious one, is habitat limitation - clearly, extremely unsuitable habitats cannot support any population. The second one is based on propagule availability (and thus corresponds to dispersal limitation). The habitat, however, affects the population in several aspects: the probability of establishment, the population growth, and population persistence. If we accept, concordantly with the metapopulation theory (Hanski 1997, 2004) that, in a stochastic environment each local population will eventually become extinct, then this aspect can be characterized by the expected time to local extinction. This is influenced not only by habitat suitability and habitat patch size (determining the carrying capacity), but also the life history of individual species, and the probability
Habitat suitability 0.3
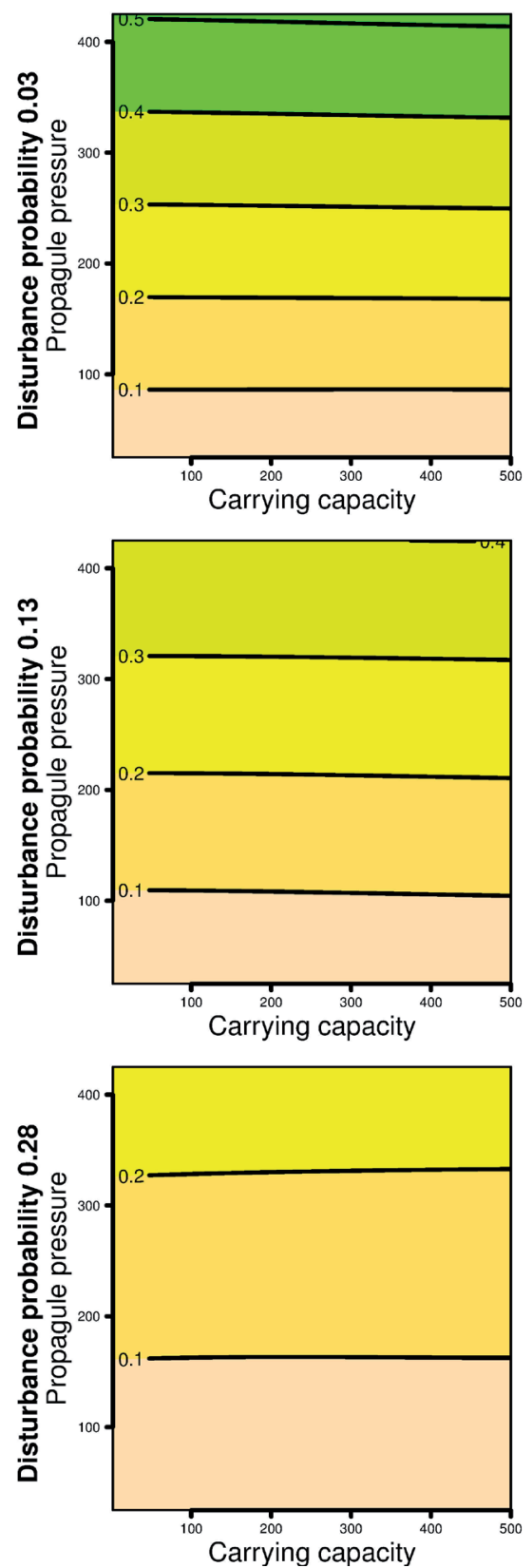

Habitat suitability 0.5
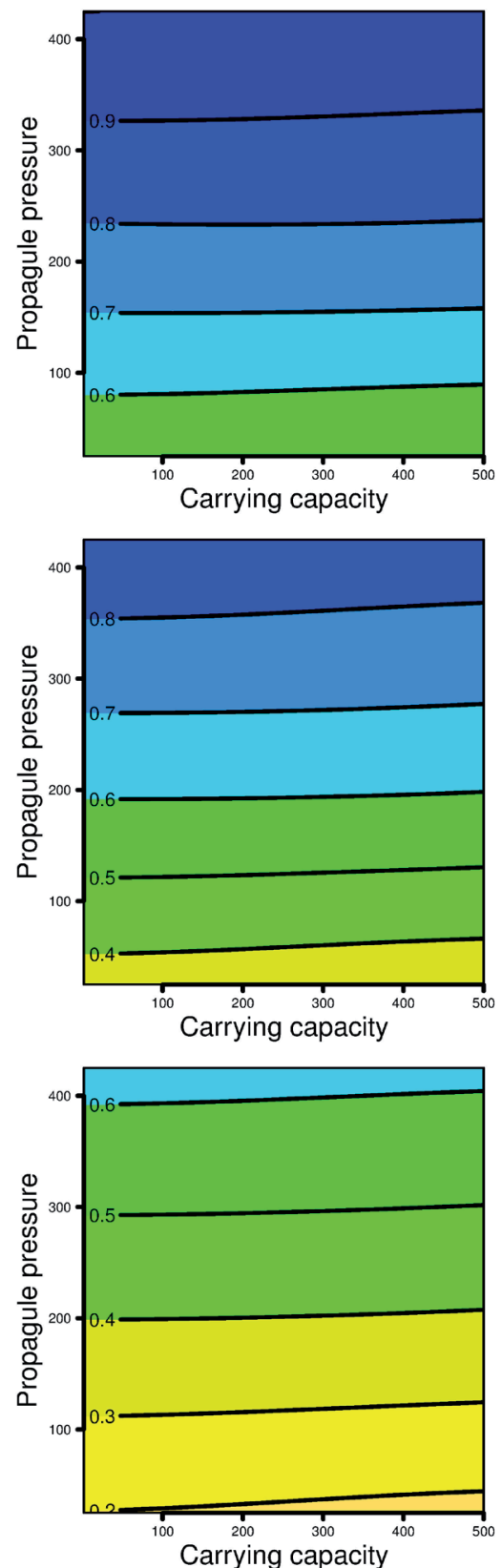

Habitat suitability 0.8
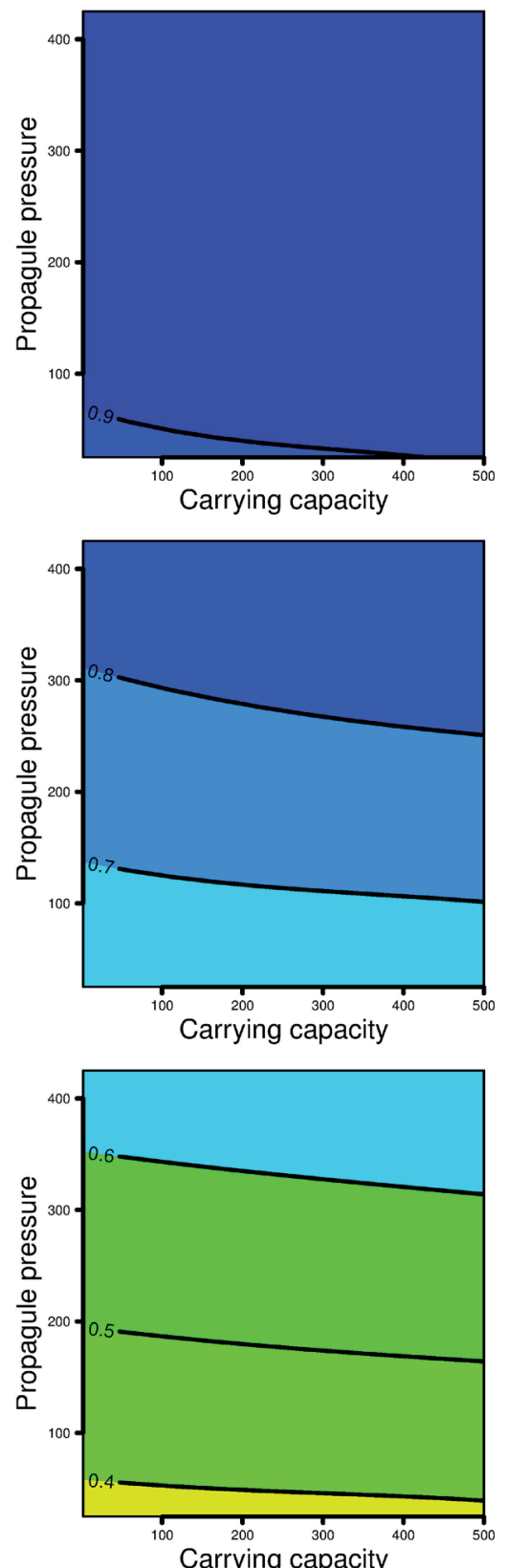

Figure 3. Proportion of sites occupied by at least one adult perennial plant from 1000 repetitions after 1000 time steps for gradients of carrying capacity, propagule pressure, disturbance probability and habitat suitability. Dark color (high proportion) describes parameter's space where mostly all simulations finished with at least one adult individual at the end, whereas light color (low proportions) corresponds to low number of simulations with adult individuals. For the definitions of parameters, see Table 1. 
of some extreme events, which would lead to local population extinction. In particular, this last aspect can be difficult to assess from short-term observations.

\section{Habitat limitation and seed input}

Distribution of a plant species is usually considered to be a result of both seed and microsite availability at the local scale, and dispersal and habitat limitation at the regional scale (Hellström et al. 2009, Münzbergová and Herben 2005,
Öster et al., 2009, Turnbull et al. 2000, Pásztor et al. 2016). Both are important in structuring plant communities, and the importance of each is species specific (Hölzel 2005, Öster and Eriksson 2012) as well as scale dependent (Münzbergová 2004). For a species, the role of both factors changes during life cycle stages (Baeten et al. 2009, Candeias and Warren 2016, Gustafsson and Ehrlén 2002, Kelemen et al. 2015, Münzbergová 2004). In our model, we have not considered the microsite limitation explicitly. Nevertheless, it is included in two ways in our model. First, the habitat suitability effect
Habitat suitability 0.3
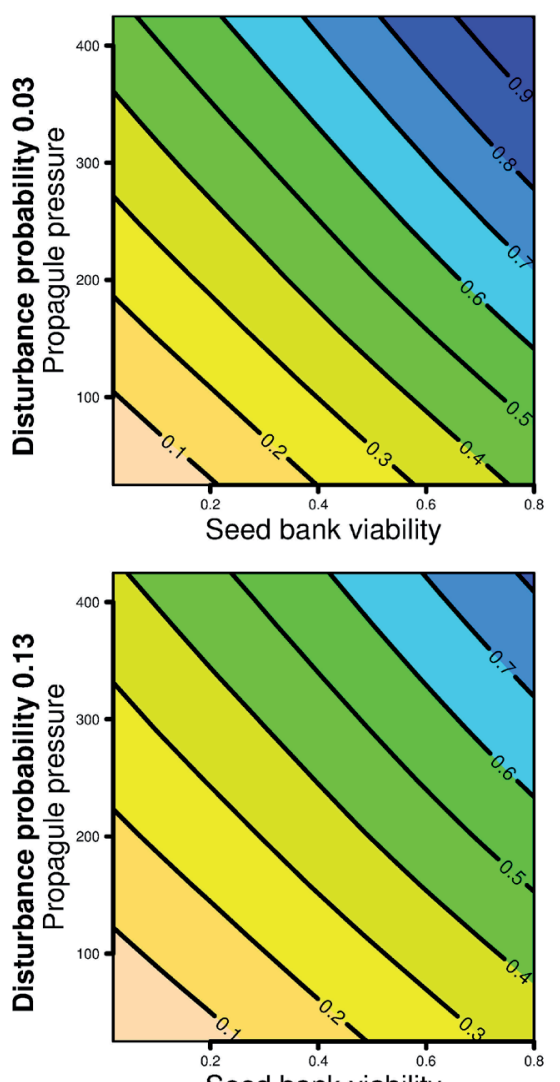

Seed bank viability

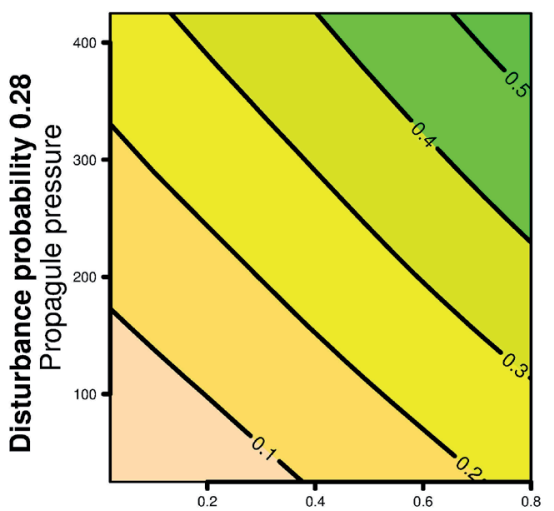

Seed bank viability
Habitat suitability 0.5
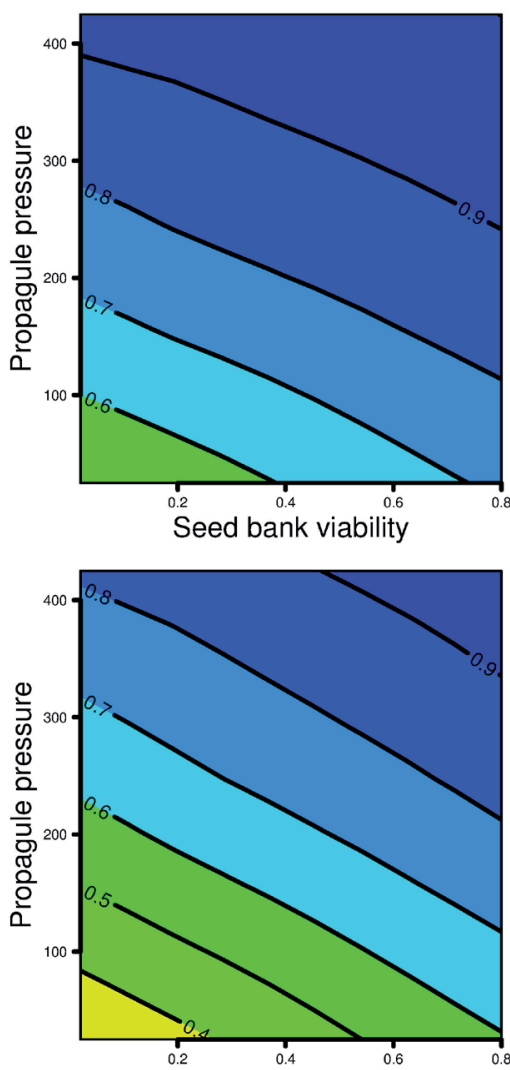

Seed bank viability

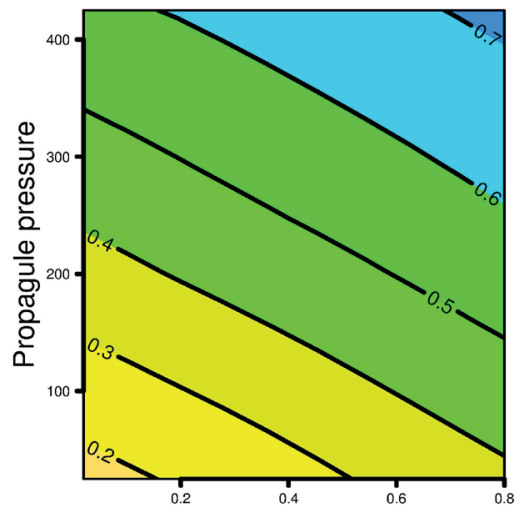

Seed bank viability
Habitat suitability 0.8
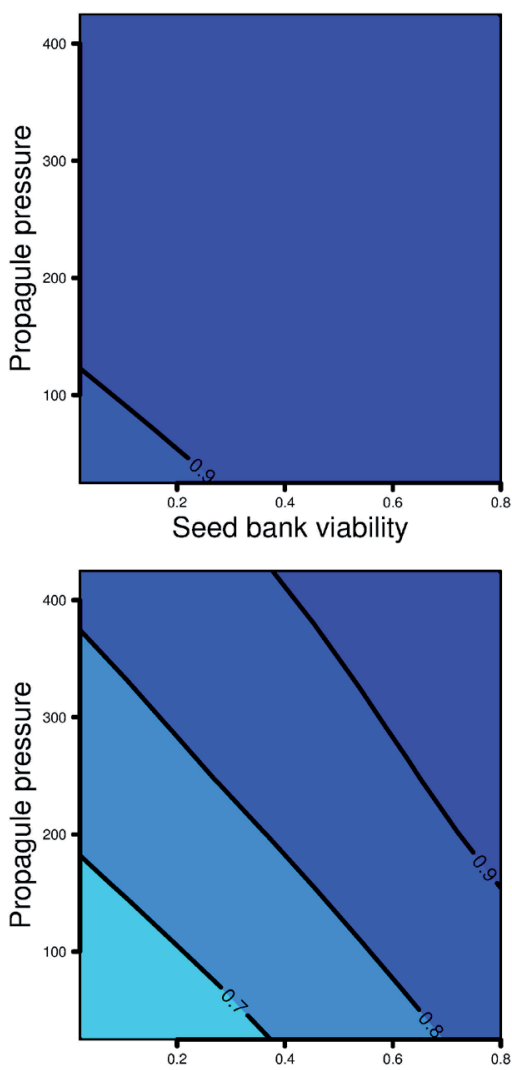

Seed bank viability

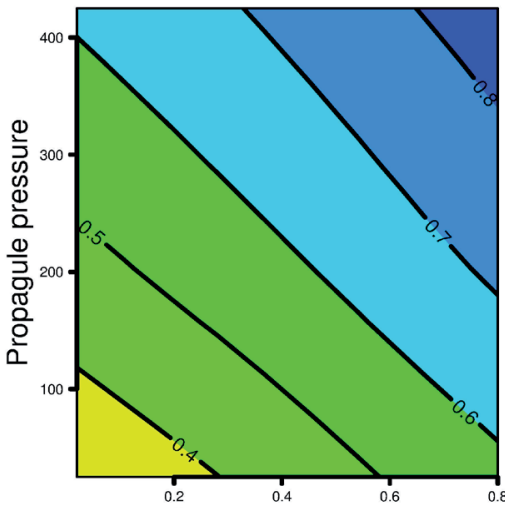

Seed bank viability

Figure 4. Proportion of sites occupied by at least one adult perennial plant from 1000 repetitions after 1000 time steps for gradients of seed bank, propagule pressure, disturbance probability and habitat suitability. Dark color (high proportion) describes parameter's space where mostly all simulations finished with at least one adult individual at the end, whereas light color (low proportions) corresponds to low number of simulations with adult individuals. For the definitions of parameters, see Table 1. 
on recruitment reflects mainly the abundance of suitable microsites (i.e., of the "safe sites" according to Harper 1977). Second, in the model, each seed has some probability to germinate and establish. In fact, the most important determinant of whether individual seeds either germinate or fail is whether it will fall to a suitable or unsuitable microhabitat. Mechanistically, it means that increasing the seed input also increases the chance that a seed reaches a suitable microhabitat.

Our results imply that the effects of lack of seed input and habitat limitation can mutually compensate each other. To demonstrate this compensation, studies where propagule pressure is manipulated are needed. Accordingly, Münzbergová (2012) found that seed input (mimicking the seed rain intensity) has a significant effect on species richness and particularly on the composition of plant communities. She suggested that different intensity of seed rain may explain differences in the composition of natural communities that cannot be attributed to habitat conditions. Similarly, several other studies concluded that establishment success is positively related to seed input (Stampfli and Zeiter 2008, Tanentzap and Bazely 2009). Nevertheless, this compensation is not absolute. Öster and Eriksson (2012) recorded a positive effect of increased propagule pressure on successful colonization only for some species. For a subset of their species, increasing propagule pressure enhanced recruitment, suggesting that these species may overcome the mortality sieve after seed arrival, provided that there is a sufficient density of propagules. However, they noted that there is still also a large subset of species that did not increase recruitment despite increasing propagule pressure, with their successful establishment dependent on niche structure. The establishment can also be affected by priority effects, when the first arriving species has higher chance to establish, and then it is difficult to be outcompeted - however, to avoid overcomplicated model, we decided not to reflect this effect in our model.

Our results also show that this compensation is dependent on many facets of the life history of individual species and on the disturbance regime of individual localities. Typically, in suitable habitats, the importance of external seed input decreases, once the habitat is colonized, provided that the locality is stable and the life history of the species supports long-term survival. There are clear examples of populations surviving at their localities for millennia without external propagule input. The relict populations from the last ice age are good examples. For example, the southernmost locality of the arctic species Rubus chamaemorus in the Krkonoše Mts., Czech Republic, Central Europe (Šourek, 1969) is clearly a relict from the last ice age, surviving there with zero propagule pressure (the closest locality is hundreds of km away). The peat-bog, where the species has survived, provides a very stable environment (so that the $e$ parameter in our model would be very close to zero) and this clonally spreading species thus has an extremely high probability of surviving (there is minimal effect of demographic stochasticity), despite the fact that the population is very small. On a much smaller temporal scale, there is an isolated locality of Erythronium denscanis in Medník (Central Bohemia, Czech Republic). The locality is hundreds of kilometers from the closest source of propagules, and the probability of propagule transfer of this large seeded species is effectively zero. Whether it is an indigenous locality, or some type of artificial introduction (most probably the latter is correct, Sádlo 2009), it is now clear that the population survived there for at least two centuries since it was first reported. These examples (and many other similar ones) demonstrate that there are habitats which are suitable for a species (particularly for species survival), and if they are not subject to severe external disturbances, these habitat islands can be continuously occupied even with zero propagule input from outside for an extensive period (since the last ice age in the case of Rubus chamaemorus). Also, both the species are able to spread vegetatively (the phenomenon not included in our model). Vegetative spreading usually increases the population persistence (Herben et al. 2014), and thus decreases the species dependence on the external seed input.

On the contrary, there are clear examples where a single artificial transfer (both intended and unintended) of a species caused its long term survival in an area, demonstrating that there are many suitable unoccupied localities. The extensive literature on invasive species (Lowry et al. 2013) provides innumerable examples, but these are mostly transfers on large spatial scales - often between continents. Nevertheless, similar outcomes can be shown on much smaller scales. Mudrák et al. (2014) and unpublished results of ours show that Rhinanthus minor, an annual hemiparasite with relatively large seeds and only short-term seed bank, when introduced to suitable localities, is able to form "permanent" viable population (our longest running record is a population viable for 15 years after introduction into suitable unoccupied habitat). It applies even to localities where the closest populations are within distances of less than five kilometers. This meadow species is highly sensitive to mowing early in the year, as this can effectively eliminate seed production (Blažek and Lepš 2015), which together with fast depletion of the seed bank leads to fast local extinction. This is an example of a species where the propagule pressure is limited by poor dispersal ability, where even high growth rate and carrying capacity (observed densities might be over 100 individuals $/ \mathrm{m}^{2}$ ) cannot compensate for the potential effect of strong disturbance (early mowing means effectively killing all of the individuals in the population, so the parameter $R$ in our model will be very close to zero). Another example (Lepš, unpublished observation) is an artificial introduction of Calla palustris (as a few vegetative ramets) into an alder carr adjacent to a fishpond in Zátluky in Eastern Bohemia, having developed a strong population surviving there for more than 40 years and documenting that this habitat is suitable for the species; nevertheless, it was probably unoccupied for centuries. The closest localities are less than $20 \mathrm{~km}$ from this site, but this distance is sufficient to prevent diaspore transfer for this species. This is a case where extremely low propagule pressure cannot be compensated by habitat suitability and dispersal limitation operates at rather short spatial scales.

The factors of habitat and dispersal limitation do not only compensate for each other, but their negative synergistic effect might worsen the decline in species distribution on the landscape scale. Typically, the oligotrophic meadows remain 
in cultural landscape mostly as isolated habitat islands. At the same time, the conditions change (e.g., due to the nitrogen depositions) so that the habitat suitability for the oligotrophic meadow species decreased. The possible local extinctions are then often irreversible, because the propagule pressure is decreased due to their isolation and also due to their scarcity in the landscape.

\section{Seed bank and disturbances}

A similar compensating relationship can also be seen between the propagule pressure and seed bank viability; species with a permanent seed bank are less dependent on propagule pressure. Indeed, arable weeds usually have poor seed dispersal, but a very persistent seed bank (Thompson et al. 1998). On the contrary, Salix seeds are one of the most efficient in long distance dispersal, but their seeds have extremely short viability (Karrenberg et al. 2002). For annual plants, propagule pressure has to be higher and is more critical in comparison with perennials: once a perennial plant population establishes at a site, we can expect continuous seed production, whereas the annuals are dependent on recurrent recruitment. Not only high propagule pressure can compensate less suitable habitat conditions, but also low propagule input can be balanced by seed bank viability, or increased fecundity.

To keep the model simple and illustrative, we have limited the number of parameters in the model and thus we also limited the number of processes reflected. The disturbance in our model is considered solely as an agent killing part of, or, whole the population. This corresponds well to, e.g., the above mentioned effect of early mowing on Rhinanthus. On the contrary, it is known that success of species establishment can be positively affected by disturbance (Špačková and Lepš 2004, Vítová et al. 2017). For many species, some disturbance is needed to recruit successfully from seeds, and this effect is not included in the model - consequently, the probability of occupancy always decreases with disturbance (so the model cannot simulate the disturbance-dependent species). In recent anthropogenic landscapes, probably, the most frequent type of "disturbance" will be a change of land use - even seemingly minor changes such as change in the first mowing date in a meadow can by fatal for some populations (Blažek and Lepš 2015).

\section{The dark diversity and the stochasticity}

The simulations show that low (unfavorable) values of a single parameter are sufficient to keep the probability of species occurrence low (particularly true for unfavorable habitats), we need optimal values of multiple parameters to obtain the probability close to one; most of the values are rather far from one. This shows that even thought that we kept some of the parameters constant in the simulations, the occurrence of species in a locality is highly stochastic phenomenon. The stochasticity of species composition is recently being more and more appreciated by plant ecologists. As a matter of fact, the dark diversity concept (Pärtel et al. 2011, Pärtel 2014) can be defined in terms of our model as a set of species that have relatively high probability, but are absent from the community. From this point of view - the dark diversity is a fuzzy set (Dubois and Prade 1988) where degree of species membership is determined by its occurrence probability. In this concept, however, the degree of membership in dark diversity will depend on which parameters we take into account, and which are considered the random variability. This distinction would be particularly important, if we would use this concept for practical nature conservation (Lewis et al. 2017).

\section{Decreasing niche breadth from the center to the margins of the area of distribution}

The present model is able to explain some well-known ecological phenomena - one of them is the decrease of the niche breadth from the center to the margins of a species distribution range (Brown 1984, Gaston and Lawton 1990). Species are able to exploit a wider range of habitats in the center of its area of distribution than on the margins. Whereas there might be more explanations for this phenomenon, one of the most parsimonious can be derived from our model: we can expect that propagule pressure decreases from the center to the margins of the area of distribution, and consequently, the chance that high propagule pressure overcomes habitat limitation in marginally suitable habitats is higher in the center.

\section{Interpretation of sowing experiment}

The results of the model have also some consequences for the interpretation of sowing experiments (where traditionally, the successful establishment is considered a proof of dispersal limitation, and establishment failure to habitat limitation). The complete failure to establish from seeds is a reliable proof of habitat limitation of establishment in the year of experiment. Nevertheless, because seedling establishment is more sensitive to weather fluctuation among years than the survival of established plants (Grubb 1977), we should have some temporal replications to show that the species is really not able to establish in the habitat. Also, we should always consider the amount of seeds generally needed for establishment, and such experiments should always be accompanied by "control species", i.e., resident species for comparison, assessing how many resident species would erroneously demonstrate "habitat limitation". At medium habitat limitation, some percentage of seeds usually gives rise to established individuals (Vítová and Lepš 2011), but it is often not clear whether it means there is a good chance that the population will survive - we usually need to at least estimate how many seeds can the established individuals produce, which could in turn help to estimate the populations growth rate. In the case of successful mass establishment, the dispersal limitation is more probable, nevertheless, we should check whether there are good reasons to consider the population viable; probably, the most reliable would be to estimate the transition probabilities for the population matrix model, and consider the population viable if the finite rate of increase (lambda) is greater than one (Caswell 2001); this would, however, usu- 
ally require several years. Although taking into account the possible effect of weather fluctuations and/or demographic stochasticity is more challenging. We should, however, also take into account the expected longevity of the population, i.e., to estimate the probability that a population will became locally extinct - and this is quite a challenging issue. Our experience (Krahulec and Lepš 1994) shows that some newly arriving species formed seemingly viable populations (with pronounced initial population increase, so that lambda estimated during the first years after introduction would undoubtedly be larger than one), but became locally extinct later on (often without any apparent cause). Some, particularly annual species show large inter-annual fluctuations, which increases the probability of their local extinction, and some are particularly sensitive to unpredictable events. For these species, the sowing experiment might be successful, even though local extinction is a consequence of environmental variability (i.e., of site conditions). For example, the annual hemiparasitic Orobanchaceae (e.g., the Rhinanthus species) typically have no permanent seed bank, and produce (for annuals) low number of relatively large seeds (Mudrák et al. 2014). This increases the probability of their local extinction (connected e.g., with irregularities in the meadow management, a factor that should be considered as a habitat characteristic); new sowing often leads to establishment of a viable population, suggesting dispersal limitation. This is usually true from a short term perspective, nevertheless, the proximate cause might be the local extinction due to management irregularities.

In any case, we should always take into account that the distinction between habitat and dispersal limitation is not a sharp one, and that the habitat (in interaction with species life history) affects both the establishment and probability of population local extinction, and both are affected not only by the current habitat characteristics, but also by their long-term variability.

Acknowledgements: Our work is supported by the Czech Science Foundation, project GB14-36079G (Centre of Excellence PLADIAS) and grant 17-05506S. Access to computing and storage facilities owned by parties and projects contributing to the National Grid Infrastructure MetaCentrum provided under the programme "Projects of Large Research, Development, and Innovations Infrastructures" (CESNET LM2015042), is greatly appreciated. We thank to F. de Bello for highly valuable comments and suggestions to the manuscript and to C. Redmond for language improvement.

\section{References}

Baeten, L., Hermy, M. and Verheyen, K. 2009. Environmental limitation contributes to the differential colonization capacity of two forest herbs. J. Veg. Sci. 20:209-223.

Blažek, P. and Lepš, J. 2015. Victims of agricultural intensification: mowing date affects Rhinanthus spp. regeneration and fruit ripening. Agriculture, Ecosystems \& Environment 211:10-16.

Brown, J.H. 1984. On the relationship between abundance and distribution of species. Am. Nat. 124:255-279.
Candeias, M. and Warren, R.J. II 2016. Rareness starts early for disturbance-dependent grassland plant species. Biodivers. Conserv. 25:2771-2785.

Caswell, H. 2001. Matrix Population Models: Construction, Analysis and Interpretation, 2nd Edition. Sinauer Associates, Sunderland, Massachusetts.

Clark, C.J., Poulsen, J.R., Levey, D.J. and Osenberg, C.W. 2007. Are plant populations seed limited? A critique and meta-analysis of seed addition experiments. Am. Nat. 170:128-142.

Clark, J.S., Lewis, M. and Horvath, M. 2001. Invasion by extremes: variation in dispersal and reproduction retards population spread. Am. Nat. 157:537-554.

Dubois, D. and Prade, H. 1988. Fuzzy Sets and Systems. Academic Press, New York.

Dupré, C. and Ehrlén, J. 2002. Habitat configuration, species traits and plant distributions. J. Ecol. 90:796-805.

Ehrlén, J., Münzbergová, Z., Diekmann, M. and Eriksson, O. 2006. Long-term assessment of seed limitation in plants: results from an 11-year experiment. J. Ecol. 94:1224-1232.

Fibich, P., Vítová, A., Macek, P. and Lepš, J. 2013. Establishment and spatial associations of recruits in meadow gaps. J. Veg. Sci. 24:496-505.

Foster, B.L. 2001. Constraints on colonization and species richness along a grassland productivity gradient: the role of propagule availability. Ecol. Letters 4:530-535.

Foster, B.L. and Tilman, D. 2003. Seed limitation and the regulation of community structure in oak savanna grassland. J. Ecol. 91:999-1007.

Gaston, K.J. and Lawton, J.H. 1990. Effects of scale and habitat on the relationship between regional distribution and local abundance. Oikos 58:329-335

Gómez-Aparicio, L. 2008. Spatial patterns of recruitment in Mediterranean plant species: linking the fate of seeds, seedlings and saplings in heterogeneous landscapes at different scales. J. Ecol. 96:1128-1140.

Grime, J.P. 1998. Benefits of plant diversity to ecosystems: immediate, filter and founder effects. J. Ecol. 86:902-910.

Grubb, P.J. 1977. The maintenance of species-richness in plant communities - importance of regeneration niche. Biol. Rev. 52:107145.

Gustafsson, C.H. and Ehrlén, J. 2002. Seed availability and recruitment of the perennial herb Sanicula europea. Ecoscience 9:526532.

Hanski, I. 1997. Metapopulation dynamics: from concepts and observations to predictive models. In.: Hanski, I., Gilpin, M. (eds) Metapopulation Biology. Academic Press, San Diego, pp 69-91.

Hanski, I. 2004. Metapopulation theory, its use and misuse. Basic Appl. Ecol. 5:225-229.

Harper, J.L. 1977. Population Biology of Plants. Academic Press, London.

Hellström, K., Ari-Pekka, H., Pasi, R. and Juha, T. 2009. Seed introduction and gap creation facilitate restoration of meadow species richness. J. Nature Cons. 17:236-244.

Herben, T. Nováková, Z. and Klimešová, J. 2014. Clonal growth and plant species abundance. Ann. Bot. 114:377-388.

Hölzel, N. 2005. Seedling recruitment in flood-meadow species: The effects of gaps, litter and vegetation matrix. Appl. Veg. Sci. 8:115-224.

Jakobsson, A. and Eriksson, O. 2000. A comparative study of seed number, seed size, seedling size and recruitment in grassland plants. Oikos 88:494-502. 
Karrenberg, S., Edwards, P.J. and Kollmann, J. 2002. The life history of Salicaceae living in the active zone of floodplains. Freshwater Biol. 47:733-748.

Kelemen, A., Lazzaro, L., Besnyői, V., Albert, Á. J., Konečná, M. Dobay, G., Memelink, I., Adamec, V., Götzenberger, L., de Bello, F., Le Bagousse-Pinguet, Y. and Lepš, J. 2015. Net outcome of competition and facilitation in a wet meadow changes with plant's life stage and community productivity. Preslia 87:347361.

Klimeš, L. 2005. A transient expansion of sown plants and diaspore limitation. Folia Geobot. 40:69-75.

Krahulec, F. and Lepš, J. 1994. Establishment success of plant immigrants in a new water reservoir. Folia Geobot. 29:3-14.

Lewis, R. J., Bello, F., Bennett, J. A., Fibich, P., Finerty, G. E., Götzenberger, L., Hiiesalu, I., Kasari, L., Lepš, J., Májeková, M., Mudrák, O., Riibak, K., Ronk, A., Rychtecká, T., Vitová, A. and Pärtel, M. 2017. Applying the dark diversity concept to nature conservation. Conservation Biol., 31, 40-47.

Lowry, E., Rollinson, E.J., Laybourn, A.J., Scott, T.E., AielloLammens, M.E., Gray, S.M., Mickley, J. and Gurevitch, J. 2013. Biological invasions: a field synopsis, systematic review, and database of the literature. Ecol. Evol. 3:182-196.

Moles, A.T. and Westoby, M. 2002. Seed addition experiments are more likely to increase recruitment in larger-seeded species. Oikos 99:241-248.

Moles, A.T. and Westoby, M. 2004. What do seedlings die from and what are the implications for evolution of seed size? Oikos 106:193-199.

Moore, K.A. and Elmendorf, S.C. 2006. Propagule vs. niche limitation: untangling the mechanisms behind plant species distributions. Ecol. Lett. 9:797-804.

Mudrák, O., Mládek, J., Blažek, P., Lepš, J., Doležal, J., Nekvapilová, E. and Těšitel, J. 2014. Establishment of hemiparasitic Rhinanthus spp. in grassland restoration: lessons learned from sowing experiments. Appl. Veg. Sci. 17:274-287.

Münzbergová, Z. 2004 Effect of spatial scale on factors limiting species distributions in dry grassland fragments. J. Ecol. 92:854867.

Münzbergová, Z. 2012. Seed density significantly affects species richness and composition in experimental plant communities. PLOS ONE 7:e46704.

Münzbergová, Z. and Herben, T. 2005. Seed, dispersal, microsite, habitat and recruitment limitation: identification of terms and concepts in studies of limitations. Oecologia 145:1-8.

Orrock, J.L., Levey, D.J., Danielson, B.J. and Damschen, E.I. 2006 Seed predation, not seed dispersal, explains the landscape-level abundance of an early-successional plant. J. Ecol. 94:838-845.

Öster, M. and Eriksson, O. 2012. Recruitment in species-rich grasslands: the effects of functional traits and propagule pressure. $J$. Plant Ecol. 5:260-269.

Öster, M., Ask, K., Cousins, S.A.O. and Eriksson, O. 2009. Dispersa and establishment limitation reduces the potential for successful restoration of semi-natural grassland communities on former arable fields. J. Appl. Ecol. 46:1266-1274.

Pärtel, M. 2014. Community ecology of absent species: hidden and dark diversity. J. Veg. Sci. 25:1154-1159.

Pärtel, M., Szava-Kovats, R. and Zobel, M. 2011. Dark diversity: shedding light on absent species. Trends in Ecol. \& Evol. 26:124-128.

Pásztor, L., Botta-Dukát, Z., Magyar, G., Czárán, T. and Meszéna, G. 2016. Theory-Based Ecology: a Darwinian Approach. Oxford University Press, Oxford.
Primack, R.B. and Miao, S.L. 1992. Dispersal can limit local plant distribution. Cons. Biol. 6: 513-519.

Sádlo, J. 2009. Erythronium dens-canis v Čechách: uvěříme původnosti? [Erythronium dens-canis in Bohemia: can we accept its native origin? In Czech.] Zprávy České Botanické Společnosti 44:1-10.

Silvertown, J. and Charlesworth, D. 2001. Introduction to Plant Population Biology. Blackwell, Oxford

Šourek, J. 1969. Květena Krkonoš. [Flora of the Krkonoše Mts. In Czech.] Academia, Praha.

Špačková, I. and Lepš, J. 2004. Variability of seedling recruitment under dominant, moss and litter removal over four years. Folia Geobot 39:41-55.

Stampfli, A. and Zeiter, M. 2008. Mechanisms of structural change derived from patterns of seedling emergence and mortality in a semi-natural meadow. J. Veg. Sci. 19:563-574.

Švamberková, E., Vítová, A. and Lepš, J. 2017. The role of biotic interactions in plant community assembly: What is the community species pool? Acta Oecologica 85:150-156.

Tanentzap, A.J. and Bazely, D.R. 2009. Propagule pressure and resource availability determine plant community invasibility in a temperate forest understorey. Oikos 118:300-308.

Thompson, K., Bakker, J.P., Bekker, R.M. and Hodgson, J.G. 1998. Ecological correlates of seed persistence in soil in the north-west European flora. J. Ecol. 86:163-169.

Turnbull, L.A., Crawley, M.J. and Rees, M. 2000. Are plant populations seed-limited? A review of seed sowing experiments. Oikos $88: 225-238$.

Vellend, M. 2016. The Theory of Ecological Communities. Princeton University Press, Princeton.

Vítová, A. and Lepš, J. 2011. Experimental assessment of dispersal and habitat limitation in an oligotrophic wet meadow. Plant Ecol. 212:1231-1242.

Vítová, A., Macek, P. and Lepš, J. 2017. Disentangling the interplay of generative and vegetative propagation among different functional groups during gap colonization in meadows. Funct. Ecol. 31:458-468.

Wellstein, C., Campetella, G., Spada, F., Chelli, S., Mucina, L., Canullo, R. and Bartha, S. 2014. Context-dependent assembly rules and the role of dominating grasses in semi-natural abandoned sub-Mediterranean grasslands. Agric. Ecosyst. Environ. 182:113-122.

Zobel, M. Otsus, M., Liira, J., Moora, M. and Möls, T. 2000. Is smallscale species richness limited by seed availability or microsite availability? Ecology 81:3274-3282.

Received October 10, 2017 Revised December 27, 2017 Accepted February 20, 2018

\section{Supplementary material}

Figure S1. Proportion of sites occupied by at least one adult perennial plant for gradients propagule pressure and disturbance probability over time.

Figure S2. Proportion of sites occupied by at least one adult annual plant from 1000 repetitions after 1000 time steps for gradients of fecundity, propagule pressure, disturbance probability and habitat suitability. 
Figure S3. Proportion of sites occupied by at least one adult annual plant from 1000 repetitions after 1000 time steps for gradients of carrying capacity, propagule pressure, disturbance probability and habitat suitability.

Figure S4. Proportion of sites occupied by at least one adult annual plant from 1000 repetitions after 1000 time steps for gradients of seed bank, propagule pressure, disturbance probability and habitat suitability.

Figure S5. Proportion of sites occupied by at least one adult perennial plant from 1000 repetitions after 1000 time steps for gradients of habitat suitability, propagule pressure, disturbance probability and fecundity.

Figure S6. Proportion of sites occupied by at least one adult perennial plant from 1000 repetitions after 1000 time steps for gradients of habitat suitability, propagule pressure, disturbance probability and carrying capacity.

Figure S7. Proportion of sites occupied by at least one adult perennial plant from 1000 repetitions after 1000 time steps for gradients of habitat suitability, propagule pressure, disturbance probability and seed bank.

Figure S8. Proportion of sites occupied by at least one adult annual plant from 1000 repetitions after 1000 time steps for gradients of habitat suitability, propagule pressure, disturbance probability and fecundity.

Figure S9. Proportion of sites occupied by at least one adult annual plant from 1000 repetitions after 1000 time steps for gradients of habitat suitability, propagule pressure, disturbance probability and carrying capacity.

Figure S10. Proportion of sites occupied by at least one adult annual plant from 1000 repetitions after 1000 time steps for gradients of habitat suitability, propagule pressure, disturbance probability and seed bank.

The file may be downloaded from www.akademiai.com. 